\title{
Lithium Battery, About Its History, Future Development, Environmental Impact and System Economics
}

\author{
Jllin Chen ${ }^{1 *}$, Xuanyao Huang ${ }^{2}$, Honglin Wang ${ }^{3}$ \\ ${ }^{1}$ Department of Chemical and Materials Engineering,Tunghai University,Taiwan,Taichung40704,China \\ ${ }^{2}$ Quanzhou No. 5 High School, Quanzhou Fujian, Quanzhou362000, China \\ ${ }^{3}$ The international High School Affiliated to Shenzhen University, Shenzhen Guangdong,518066, China \\ *Correspond author Email: cjl20000810@gmail.com
}

\begin{abstract}
Lithium batteries are an essential component to a zero-carbon energy transition around the world. In this paper, we will discuss six parts about the lithium battery. About the history of lithium battery, introduce how it was invented and widely used by people all over the world, what fields it is mostly used in, its future development, how people will solve some existing problems, and how to use the battery most effectively. This report also describes the impact of today's lithium battery on the environment such as the waste of lithium batteries. And about secondly used lithium batteries' system economics.
\end{abstract}

Keywords: application field, reuse, development, waste

\section{INTRODUCTION \& HISTORY}

The concept of lithium-ion battery is put forward by British chemist M. Stanley Whittingham, who is now working at Binghamton University. Whittingham began his research at Stanford University, which allowed him to achieve breakthrough results. In the early 1970s, he figured out how to store lithium ions in disulfide material layer. Titanium(IV) sulfide and lithium metal was used as the electrodes by Whittingham. Such rechargeable lithium batteries, however, will never become a reality. Because of its characteristics, it must be synthesized under completely sealed conditions and is very expensive. So titanium disulfide was a very bad choice (Titanium disulfide raw materials in the 1970s cost about $\$ 1,000$ per kilogram). When titanium disulfide is exposed to air, it reacts to form hydrogen sulfide compounds, which produce an unpleasant smell and are toxic to most animals. Exxonmobil stopped developing the Whittingham lithium-titanium disulfide battery for this and other reasons. Batteries with metallic lithium electrodes have safety issues because metallic lithium reacts with water and releases flammable hydrogen gas. As a result, research has moved on to developing batteries in which only lithium compounds, not metallic lithium, can receive and release lithium ions.[1]
In 1974-1976, J. O. Besenhard of TU Munich discovered the interchangeable phenomenon between graphite layer and cathode oxide layer. Besenhard pointed to its use in lithium batteries. The decomposition of electrolyte and the co-intercalation of solvents would seriously affect the life of the battery in the early stage.[1]

\section{Development}

In 1973, Adam Heller introduced lithium thionyl chloride batteries, which are still used to implant medical devices and defense systems that require a storage life of more than 20 years, high energy density and/or tolerance to extreme operating temperatures.[2]

1977 - Samar Basu demonstrated electrochemical intercalation of lithium in graphite at the University of Pennsylvania. This discovery prompted Bell Laboratories (LiC) to develop a viable lithiumintercalated graphite electrode, thereby providing an alternative to lithium metal electrode batteries.[2]

In 1979, Ned A. Godshall et al., and soon after, John B. Goodenough (University of Oxford) and Koichi Mizushima(University of Tokyo) used lithium cobalt oxide (LiCoO2) as a positive electrode, Lithium metal as a negative electrode shows a rechargeable lithium battery in the voltage range of $4 \mathrm{~V}$. This innovation 
provided cathode materials for early commercial lithium batteries. $\mathrm{LiCoO} 2$ is a stable cathode material as a lithium ion donor, which means it can be used in addition to metal lithium anode materials. Using a stable and easy to operate anode material, $\mathrm{LiCoO} 2$ supports new rechargeable battery systems. Through further identification, Godshall et al. determined the similar value of ternary compound lithium-transition metal-oxides like the spinel LiMn2O4, Li2MnO3, $\mathrm{LiMnO}$, $\mathrm{LiFeO}$, $\mathrm{LiFe} 5 \mathrm{O}$, and $\mathrm{LiFe} 5 \mathrm{O} 4$ (and later lithium-copper-oxide and lithium-nickel-oxide cathode materials in 1985)[2]

In 1980, Rachid Yazami (Rachid Yazami) invented the lithium graphite electrode (anode) by demonstrating the reversible electrochemical intercalation of lithium in graphite. The organic electrolyte available at the time would decompose when the graphite anode was used for charging. Using a solid electrolyte, Yazami demonstrated that lithium can be inserted reversibly into graphite by an electrochemical mechanism. By 2011, Yazami's graphite electrodes had secured a place in commercial lithium-ion batteries.[2]

Yamabe discovered the negative electrode, which originated from PAS (polystyrene semiconductor material) and was discovered by Yamada Kenhisa in the early 1980s. This technology sprouted from the conductive polymer discovered by Professor Hideki Shirakawa and his team. It can also be said that it originated from the polyacetylene lithium-ion battery developed by Alan MacDiarmid and Alan J. Heeger.[2]

In 1983, manganese spinel Mn2O4 that was used as a charging cathode material for lithium-ion batteries, was developed by Michael M. Hackray, Peter Bruce, William David and John B.Goodenough. During discharge, it has two flat platforms, one at $4 \mathrm{~V}$ with a stoichiometric ratio of LiMn2O4 and one at $3 \mathrm{~V}$ with a final stoichiometric ratio of $\mathrm{Li} 2 \mathrm{Mn} 2 \mathrm{O} 4 .[2]$

In 1985, Akira Yoshino used carbon materials to assemble a prototype battery in which one electrode can be inserted into lithium ions, and the other electrode can be inserted into lithium cobalt oxide ( $\mathrm{LiCoO} 2)$, which had dramatically improved security. LiCoO2 technology makes the industrial scale production and commercial application of lithium-ion batteries possible.[2]

In 1989, Arumugam Manthiram and John B. Goodenough discovered a polyanionic cathode. They showed that, due to the inductive effect of polyanions, the positive electrode containing polyanions, such as sulphates, generates a higher voltage than the oxide, which include materials such as lithium iron phosphate.[2] (conclusion/summary of introduction/history chapter)

Li-ion batteries were first proposed by M.S. Whittingham of Binghamton University in the 1970s.
1. Whittingham adopted titanium(II) sul-fide as the cathode while adopted lithium metal as the anode. In 1980, Rachid Yazami et al. first discovered the electrochemical properties of lithium embedded graphite by demonstrating the reversible process of lithium embedded graphite in a lithium/polymer electrolyte/graphite half battery. 2. In 1981, Bell LABS developed a graphite anode with feasibility to act as an alternative to lithium-metal batteries. After a team led by John Goodenough conducted cathode research, Iin 1991 SONY released the first commercially available lithium-ion battery, using layered oxide chemistry, specifically lithium cobalt oxide. In 1983, Dr. Michael Thackeray, Dr. Goodenough and colleagues discovered that manganese spinel could be used as a cathode material. Due to the low cost, good electronic and lithium ion conductivity, and three-dimensional structure, spinel has good structural stability and therefore has great prospects. Manganese spinel is now widely used in commercial batteries, and it can be overcome by chemical modification of the material, although high purity manganese spinel will fade as it cycles.[3]

In 1989, goodenough proved that due to the induction effect of polyanions, cathodes containing polyanions, such as sulfate, will produce higher voltage than oxides. 4. In 1996, lithium iron phosphate (LiFePO4) and other olivine phosphates (lithium metal phosphates with an olivine structure) were identified as a cathode material by Goodenough, Akshaya Padhi and colleagues. In 2002, Yet-Ming Chiang of the Massachusetts Institute of Technology and his team improved the conductivity of lithium battery materials by doping aluminum, niobium and zirconium, thereby substantially improving the performance of lithium batteries. The exact mechanism that led to the increase is the subject of a debate. In 2004, Chiang used iron phosphate particles less than 100 nanometers in diameter again to improve performance, which has reduced the particle density by nearly a hundred times, increasing the surface area of the cathode and improving capacity and performance.[3]

In recent years, due to the rapid development of nanotechnology, nanomaterials have gradually become an excellent choice for lithium ion battery materials. As an electrode material for lithium-ion batteries, nanomaterials have unique physical and chemical properties, including large surface area, short transport length, large reversible capacity, and long cycle life, which can significantly improve the performance of lithium ion batteries such as specific capacity and high rate.[3]

\section{APPLICATION OF LITHIUM BATTERY}

Nowadays, the application of lithium-ion battery has been more and more widely used. Lithium batteries are 
widely used in energy storage systems such as hydraulic, thermal, wind and solar power stations, as well as electric tools, electric bicycles, electric motorcycles, electric vehicles, military equipment, aerospace and many other fields.

At present, lithium batteries have been gradually extended to electric bicycles, electric vehicles and other fields. Next, we will introduce several industries of lithium-ion battery applications.

Since its establishment in 1990, it has been deeply loved by $3 \mathrm{C}$ digital, electric tools and other industries because of its advantages such as high energy density, high voltage, environmental protection, long service life and fast charging speed, and has made a particularly prominent contribution to the new energy vehicle industry. As the power source of new energy vehicles, lithium-ion battery industry has great market potential and is an important part of national strategic development. It is estimated that the industrial scale will exceed 160 billion yuan in the next 5-10 years.

As the core component of new energy vehicle, the quality of power lithium-ion battery directly determines the performance of the whole vehicle. Lithium ion battery manufacturing equipment generally includes front-end equipment, middle-end equipment and backend equipment. Its equipment accuracy and automation level will directly affect the processing efficiency and consistency of products. As a substitute of traditional welding technology, laser production technology has been widely used in lithium battery manufacturing equipment.

In the battery industry, green environmental protection has always been a technology to overcome industry problems. Lithium battery has always been the first choice of green battery. With the continuous improvement of production technology and cost compression, lithium batteries have been widely used in many fields in recent years. So what are the applications of lithium batteries in China?

The application fields of lithium battery mainly include five aspects:

1. The field of traffic power supply mainly includes (Electric vehicle etc.)

2. The field of electric energy storage power supply mainly includes (Large scale solar / wind power energy storage systems etc.)

3. The field of mobile communication power supply mainly includes (Integrated lithium battery power supply for Acer station etc.)

4. New energy storage power supply (Solar street lamp, lawn lamp, miner's lamp, emergency lamp, courtyard lamp and high pole lamp etc.)
5.Aerospace special power supply (Power supply for large ships etc. ) [4]

\section{ProspeCt OF LithiUM BATTERY}

1. New energy vehicles promote the rise of lithiumion battery packs

Because new energy vehicles are becoming more and more important in this society, the lithium-ion battery industry has also been further developed and reformed. Because of the increasing proportion of lithium-ion batteries in China's new energy vehicles, the lithium-ion battery market has a broader development space, and the lithium-ion power lithium battery market is also entering a rising period. Compared with traditional batteries, lithium-ion batteries have larger capacity under the same capacity, and have the characteristics of green and environmental protection in the process of production, use and recycling. Therefore, lithium ion batteries have been widely used in the field of consumer electronics and energy storage products.

2. The development of energy storage technology promotes the progress of power lithium-ion battery industry

Energy storage technology is the strategic support for the transformation of energy structure and the transformation of power production and consumption mode in the future. Driven by the development and commercialization trend of energy storage technology, the power lithium-ion battery, as one of the protagonists of the new energy industry, will also usher in new development opportunities. The large-scale development of energy storage technology will also promote the extension and integration of lithium-ion battery industry chain, promote the connection between the upstream, middle and downstream of power lithiumion battery industry and capital, synchronize with the market and achieve mutual benefit.

3.The development of the new energy vehicle industry has not finalized and standardized the specifications and standards of the power lithium-ion battery and battery module used, resulting in the incompatibility of many specification systems. The current process flow and manual operation restrict the processing rhythm and efficiency of the company, so it is unable to effectively improve the product quality and output. Therefore, it is very necessary to improve the automation level of power lithium-ion battery module assembly. Nowadays, to realize the intelligent processing method of whole line equipment + robot + software control, we should not only deal with the problems of compatibility, whole line beat and efficiency that users focus on, but also deal with the problems of small batch and many specifications of users' battery pack orders. 
Management software. The whole MES system directly builds the production line into a quasi unmanned processing workshop. As long as the manual materials are supplemented outside the line, it not only improves the safety, but also reduces the human intervention. In the welding process, as long as the laser welding process data is integrated into the MES management software system, it is convenient for users to call and switch directly. From the cell to pack, the parameters, data and other incoming material information of each process can be quickly queried and solved in time through the MES system. It is necessary to not only control the process, but also effectively ensure the processing efficiency. The user also realizes remote monitoring and management through the reserved industrial communication interface, which fully reflects the manufacturing characteristics of intelligent automation. Products equipped with laser processing methods have developed towards the trend of high intelligence and high automation.[5]

\section{FUTURE DEVELOPMENT DIRECTION OF LITHIUM ION BATTERY PACK}

1.Standardization and automation of production process

In the future, the manufacturing of power lithium battery will develop in the direction of "three highs and three modernizations", that is, high quality, high efficiency, high stability, informatization, unmanned and visualization. China's lithium-ion battery pack companies must also invest more resources to accelerate the intelligent manufacturing of lithium-ion battery packs through technological innovation, automatic production and standardized management.

2.High specific energy is the main development trend of power lithium battery

Companies and institutions at home and abroad are studying how to improve the energy density of power lithium batteries, so as to improve the mileage of new energy vehicles.
3.Realize technical upgrading of thermal management and BMS system on the premise of safety

4.The development of new energy is the general trend. Automobile companies have also made their own calculations and invested a lot of material and financial resources to preempt. Industry stakeholders are also optimistic that new energy vehicles are expected to double in 16 years, and the output of new energy vehicles will continue to expand. There is no doubt that the advantages of new energy development outweigh the disadvantages. When most people mention new energy vehicles, they can always say a series of advantages. As for the disadvantages brought by development, they know very little.[6]

\section{ENVIRONMENTAL IMPACT}

Nowadays, due to the high weight energy density of lithium-ion batteries(LIBs), the ability to reduce the memory effect and support a large number of charge and discharge cycles, they are diffusely used in modern technical equipment, electric and hybrid vehicles.[7]The LIBs market also started from small-scale applications to high-capacity sectors, such as electric vehicles (EV) and energy storage systems (ESS) to reduce greenhouse gas emissions and oil dependence or address the intermittent nature of alternatives green energy.[8]Because of the short life span (3-8 years),its expected to exceed 25 billion units and 500 thousand tons of LIBs will be wasted in 2020.In addition, These LIBs' certain will cause serious harm to human health and the environment.[9]As to the portable batteries, in fact, only $30 \% \sim 50 \%$ of the population dispose LIBs in the correct way.However,the presence of metallic lithium due to incorrect cycling of the battery, the high degree of reaction with moisture, and the internal presence of flammable electrolyte may cause in mechanical damage, overheating or Degradation, causing harm to people.[10] The following Table contains the main numbers of LIBs market and waste production.

Table1; main numbers of LIBs market and waste production

\begin{tabular}{llll}
\hline $\begin{array}{lll}\text { Cell } \\
\text { components }\end{array}$ & Chemical composition & \%wt. & Additional information \\
\hline External casing & Fe-Ni alloy & $20-26$ & Steel case is typical of cylindrical cells. \\
& $\mathrm{Al}$ & 10 & Aluminium case is found in prismatic cells. \\
$\begin{array}{l}\text { Cathode } \\
\text { Aluminium }\end{array}$ & Al Current collector foil & $5-8$ & \\
$\begin{array}{l}\text { Binder } \\
\text { Usually PVDF }\end{array}$ & $1-2$ & Alternatives: PTFE, butadiene-styrene rubber \\
& & & (SBR) or
\end{tabular}


Metal oxide Li

Polymeric

separator

Electrolyte

Li salts

Organic DMC-EC, PC-DME, BL-THF

solvents

Anode

Copper

Binder
LNO (LiNiO2)
$\mathrm{Ni}$

NCA

$\left(\mathrm{LiNi}_{0.8} \mathrm{CO}_{0.15} \mathrm{Al}_{0.05} \mathrm{O} 2\right)$

$\mathrm{Mn} \quad \mathrm{LMO}(\mathrm{LiMnO})$

$\mathrm{NMC}\left(\mathrm{LiNi}_{x} \mathrm{CO}_{y} \mathrm{Mn}_{z} \mathrm{O} 2\right)$

Microporous PP or PE

LiPF6, LiAsF6, LiClO4, LiBF4

$1.5-7$

$5-20$

$5-10$

5

$4-10$

$10-15$

$15-25$

$\mathrm{Cu}$ Current collector foil

Usually PVDF
8-10

$1-2$

$15-17$
LCO gives better performances but is highly expensive.

It is replaced by NMC, LMO (where Mn gives structural stability)

or C-coated LFP (LiFePO4) that is safer.

EC is the most used organic solvent, combined with others

to lower its high melting $T$.

LiPF6 has high conductivity in any medium.

Inert, thermo-resistant and current-resistant

binder

helping the adhesion.

Low storage capacity of graphite (372 mAh/g).

Alternatives: C-NT, Sn compounds, metallic NP.

Table1 [7]

Therefore, the application and production of LIB will also maintain an upward trend in the near future, which forces the world to focus on how to solve the problems after its use.[7] It ought to be recycled. However, it is unclear which recycling processes have the least environmental impact.Through research on several recycling companies around the world, and compared the life cycles of two different recycling processes (hydrometallurgy and coke metallurgy) to understand the relevant environmental impacts. This study shows that power generation, plastic incineration, and landfill have the greatest impact on the environment. The process that uses low temperature and recyclable plastic is the most environmentally friendly process (for the environment only).[11]

With the development of electric vehicles and portable lithium batteries, the supply of lithium resources has greatly increased, which will lead to a significant increase in the mining volume of lithium mines. At the same time, the mined ore must undergo a series of processing to get the desired Lithium compound. However, these mining and processing processes can also cause damage to the environment, such as interference to the groundwater layer, and the discharge of waste water containing toxic compounds. At the same time, the siliceous dust generated during the mining process will also harm the health of workers.

Apart to ores, lithium carbonate can also be produced by evaporation and washing of sodium carbonate in a large polyvinyl chloride (PVC) lined shallow pool.The environmental impact of evaporation ponds maybe lower than that of lithium ore mining. Nevertheless, when discussing how to manage lithium resources sustainably through recycling and additional technologies, it is vital to include environmental factors.

Overall, we may face a shortage of lithium with environmental and economic results. Providing sufficient funds for lithium recycling projects to help its development is what the government needs to work on next.The immediate implementation of lithium recycling is very necessary because it can reduce resource development costs and environmental impact. In view of the fact that lithium recycling does not solve the problem of resource shortage, it is necessary to add alternative energy solutions.In addition, because lithium consumption continues to grow, it must be sustainable, and effective recycling is essential.[12]

\section{SYSTEM ECONOMICS}

LIBs are the most important one of all batteries. It provides the core of power for today's hottest products, electric vehicles, and drives the development of related 
industries. At the same time, it is also the best choice for portable batteries. Obviously it has a great impact on the economy.And the establishment of a circular economy is absolutely important for sustainable development.

Firstly,in the process of reuse and recovery of LIBs, new and expanded market opportunities will be given, creating jobs, mentaning the stable supply chain.The secondary utilization of LIBs can reduce the disposal of reusable products, and because the recycling of LIBs can better prevent useful materials from being treated as waste in landfills.In plus, companies participating in environmentally sustainable business practices such as reuse and recycling may conversely increase consumer confidence in secondary market products and enhance overall competitiveness in the markets.[13]. Furthermore, the depletable resource which includes public material and the projects are used to testify how the quality, the property, the safety, and techinical viability of recycled and refurbished LIBs. This will cause some effect towards consumer trust and confidence in the recycle of LIBs in mobile and also the atationary application. [13] This means that the reuse of lithium-ion batteries will be unacceptable, leading to waste. Besides, LIBs' recovery can reduced negative environmental impacts.Compared with the total energy required for landfills, the generation of greenhouse gases and other environmental pollutants, and the extraction, transportation, refining and manufacturing of ores, it includes reducing waste and saving $51.3 \%$ of natural resources.[13]At the same time, it can also reduce the consumption of the earth's lithium resources and prevent various problems caused by the scarcity of lithium resources.

Lastly,due to the particularity of lithium batteries, the emergence of lithium batteries has also led to the development of related scientific research. As the main energy source for today's hottest electric vehicles, major manufacturing companies have their own unique lithium-ion battery technology. In this competitive environment Next, science and technology will usher in great progress.

\section{SUMMARY AND CONCLUSIONS}

In this article, LIB is discussed from multiple perspectives, from history to application, and it's future and to economics and environmental impacts. It gives a general overview of the current development and research of LIB. Although the laser welding process in China is becoming more and more mature, the highquality power LIB still needs the close cooperation of manufacturer designers and laser welding technicians to optimize the design from the aspects of material, shape, thickness, process and real-time testing, so as to achieve the ideal welding effect.As the sales and output of electric vehicles continue to rise, the demand for lithium batteries as its main energy core is also increasing. This will cause a large number of lithium batteries to be scrapped in the next few years. If they cannot be recycled correctly, it will cause great harm to the environment and human health.Through the two recovery methods studied in this article,it is also not clear which recycling processes have the lowest impact on environment.We should try to find a better way to recycling the LIBs or use other materials with lower environmental impact.However, today, there are many technical, economic, and regulatory factors that inhibit a circular economy for LiBs around the world.This needs to be overcome by the joint efforts of the government and society in the future.Hope in the future we can found a good way to balance these parts of problems.

\section{REFERENCES}

[1]Lithium-ion battery-

Wikipedia,https://en.wikipedia.org/wiki/Lithiumion_battery

[2]ScienceDirect:Lithium Ion Battery

[3]AmplifyETFs.com,History of Lithium-Ion Batteries,855-267-3837|(855-AMP-ETFS)

[4]http://www.juda.cn/news/53895.html(2021)

[5] http://www.juda.cn/news/207509.html(2021)

[6] http://www.juda.cn/news/168626.html(2021)

[7]Elena Mossali, Nicoletta Picone, Luca Gentilini, Olga Rodrìguez, Juan Manuel Pérez, Marcello Colledani .Lithium-ion batteries towards circular economy: A literature review of opportunities and issues of recycling treatments https://doi.org/10.1016/j.jenvman.2020.110500

[8] Kim, T., Park, J., Chang, S.K., Choi, S., Ryu, J.H., Song, H., 2012B. The current move of

lithium ion batteries towards the next phase. Adv. Energy Mater 2, 860-872.

[9] Yu, J., He, Y., Ge, Z., Li, H., Xie, W., Wang, S., 2018. A promising physical method for

recovery of $\mathrm{LiCoO} 2$ and graphite from spent lithium-ion batteries. Grinding

flotation" Separation and Purification Tech. 190, 45-52.

[10] Sonoc, A., Jeswiet, J., Soo, V.K., 2015. Opportunities to Improve Recycling of

Automotive Lithium Ion Batteries" the 22nd CIRP Conference on Life Cycle

Engineering. Procedia CIRP vol. 29, 752-757.

[11] Anna Boyden, Vi Kie Soo, Matthew Doolan, 
2016.The Environmental Impacts of Recycling Portable Lithium-Ion Batteries" the 23rd CIRP Conference on Life Cycle Engineering Procedia CIRP 48 ( 2016 ) 188 - 193

[12] Thomas Cherico Wanger, 23 March 2011.The Lithium future-resources, recycling, and the environment, https://doi.org/10.1111/j.1755263X.2011.00166.X

[13]Taylor L. Curtis, Ligia Smith, Heather Buchanan, and Garvin Heath,March 2021,A Circular Economy for Lithium-Ion Batteries Used in Mobile and Stationary Energy Storage: Drivers, Barriers, Enablers, and U.S. Policy Considerations,NREL/TP-6A20-77035, https://www.nrel.gov/docs/fy21osti/77035. 